\title{
Cloning of human and mouse genes homologous to RAD52, a yeast gene involved in DNA repair and recombination
}

\author{
Daan F.R. Muris ${ }^{a}$, Olga Bezzubova ${ }^{b}$, Jean-Marie Buerstedde ${ }^{b}$, Kees Vreeken ${ }^{a}$, \\ A.S. Balajee ${ }^{\mathrm{a}}$, Chris J. Osgood ${ }^{\mathrm{a}, \dagger}$, Christine Troelstra ${ }^{\mathrm{c}}$, Jan H.J. Hoeijmakers ${ }^{\mathrm{d}}$, \\ Kai Ostermann ${ }^{\mathrm{e}}$, Henning Schmidt ${ }^{\mathrm{e}}$, A.T. Natarajan ${ }^{\mathrm{a}}$, Jan C.J. Eeken ${ }^{\mathrm{a}}$, \\ Paul H.M. Lohman ${ }^{\text {a }}$, Albert Pastink ${ }^{\mathrm{a}, *}$ \\ ${ }^{a}$ Medical Genetics Centre South-West Netherlands, Department of Radiation Genetics and Chemical Mutagenesis, \\ State University of Leiden, Wassenaarseweg 72, 2333 AL Leiden, The Netherlands \\ ${ }^{\mathrm{b}}$ Basel Institute for Immunology, Grenzacherstrasse 487, CH-4005 Basel, Switzerland \\ ${ }^{\mathrm{c}}$ Department of Radiotherapy, Division of Clinical Radiobiology, Dr. Daniël den Hoed Centre, Groene Hilledijk 301, \\ 3075 EA Rotterdam, The Netherlands \\ ${ }^{\mathrm{d}}$ Medical Genetics Centre South-West Netherlands, Department of Cell Biology and Genetics, Erasmus University, P.O. Box 1738, \\ 3000 DR Rotterdam, The Netherlands \\ ' Institute of Genetics, TU Braunschweig, Spielmannstrasse 7, D-38106 Braunschweig, Germany
}

Received 25 July 1994; accepted 1 August 1994

\begin{abstract}
The RAD52 gene of Saccharomyces cerevisiae is required for recombinational repair of double-strand breaks. Using degenerate oligonucleotides based on conserved amino acid sequences of RAD52 and rad22, its counterpart from Schizosaccharomyces pombe, RAD52 homologs from man and mouse were cloned by the polymerase chain reaction. DNA sequence analysis revealed an open reading frame of 418 amino acids for the human RAD52 homolog and of 420 amino acid residues for the mouse counterpart. The identity between the two proteins is $69 \%$ and the overall similarity $80 \%$. The homology of the mammalian proteins with their counterparts from yeast is primarily concentrated in the N-terminal region. Low amounts of RAD52 RNA were observed in adult mouse tissues. A relatively high level of gene expression was observed in testis and thymus, suggesting that the mammalian RAD52 protein, like its homolog from yeast, plays a role in recombination. The mouse RAD52 gene is located near the tip of chromosome 6 in region G3. The human equivalent maps to region p13.3 of chromosome 12 . Until now, this human chromosome has not been implicated in any of the rodent mutants with a defect in the repair of double-strand breaks.
\end{abstract}

Keywords: Human RAD52 homologue; Mouse RAD52 homologue

\section{Introduction}

\footnotetext{
* Corresponding author. Fax 71-221615; Tel. 71-276153.

† Present address: Department of Biological Sciences, Old Dominion University, Norfolk, VA 23529-0266, USA.
}

Double-strand breaks (DSBs) in DNA arise as intermediates in several cellular processes including gene rearrangement during lymphocyte differ- 
entiation and recombination, or may be induced by DNA-damaging agents such as ionizing radiation. Numerous studies have implicated radiation-induced DSBs in the induction of chromosomal aberrations and in cytotoxicity. Direct evidence that DSBs can lead to chromosomal aberrations and intragenic alterations has come from studies showing that restriction enzymes induce chromosomal rearrangements and mutations when introduced into mammalian cells (Bryant, 1984; Natarajan and Obe, 1984; Winegar et al., 1989; Winegar et al., 1992).

To study the repair of DSBs in mammalian cells, several X-ray-sensitive rodent cell lines have been isolated. To date, at least nine complementation groups are known (for a review, see Collins, 1993). Among them, three groups are defective in the repair of DSBs: xrs (Kemp et al., 1984; Weibezahn et al., 1985), XR-1 (Giaccia et al., 1985), and V-3 (Whitmore et al., 1989). The identification of complementing human chromosomes by microcell-mediated chromosome transfer is a first step towards the identification of human genes involved in DSB repair. X-ray repair crosscomplementing (XRCC) gene 4, which complements XR-1 cells, is located on chromosome 5 (Giaccia et al., 1990). XRCC5 is located on chromosome 2 and complements xrs cells (Chen et al., 1992; Jeggo et al., 1992). Cell lines derived from mice affected by the severe combined immune deficient (scid) mutation also have a reduced capacity of DSB repair and are sensitive to X-ray radiation (Biedermann et al., 1991; Hendrickson et al., 1991). The scid mice are characterized by a defect in one of the terminal steps of immunoglobulin rearrangement (Bosma and Carroll, 1991). The human gene complementing the scid defect is located on chromosome 8 (Itoh et al., 1993; Komatsu et al., 1993; Kirchgessner et al., 1993; Kurimasa et al., 1994). Recently, it has been shown that scid cells belong to the same complementation group as the Chinese hamster CHO mutant V-3 (Taccioli et al., 1994; Zdzienicka, personal communication). Cell lines derived from patients suffering from ataxia telangiectasia (AT) or Nijmegen Breakage Syndrome (NBS) are characterized by radiation sensitivity. However, the repair of DSBs is normal in AT cells, though the fidelity of repair appears not to be optimal (Fornace and Little, 1980; Hariharan et al., 1981; Van der Schans et al., 1980; Jaspers et al., 1982; North et al., 1990). No data have been reported on the repair of breaks in NBS cells.

In each organism several mechanisms are present to repair DSBs in DNA. In addition to endto-end rejoining, DSBs can be repaired by resection-annealing or by recombinational repair (Price, 1993). The first step in the resection-annealing process (also called single-strand annealing) is an exonucleolytic degradation of the $5^{\prime}$ termini leaving $3^{\prime}$ single-strand tails. If repeats are present on both sites of the break, annealing of the single strands may occur. After further exonucleolytic processing of the branched intermediates, the remaining strands are rejoined by ligation. As a consequence of this type of repair, deletions are introduced in the DNA. The recombinational repair mechanism (also called doublestrand break repair or gap repair) requires a second, undamaged homologous sequence. After pairing and strand invasion, information of the homologous sequence is used to repair the break.

In the yeast Saccharomyces cerevisiae, genes belonging to the RAD52 epistasis group ( $R A D 50$ 57, XRS2 and probably also MRE11) are required for the recombinational repair of DSBs (Friedberg, 1988; Game, 1993; Ivanov et al., 1992; Ajimura et al., 1993). Mutants of this epistasis group have been isolated on the basis of their sensitivity towards ionizing radiation and methyl methanesulfonate. The most extreme sensitivity to $\mathrm{X}$-rays is shown by rad51, rad52 and rad54 mutants. Thus far, only for these three mutants has direct molecular evidence been substantiated for a defect in DSB repair (Game, 1993). The rad51, 52 and 54 mutants are also defective in induced mitotic recombination and in mating-type switching. Meiotic recombination is affected in rad51 and rad52 mutants, as manifested by the formation of inviable spores. Several of the RAD52 group genes have been isolated and characterized (Alani et al., 1989; Aboussekhra et al., 1992; Basile et al., 1992; Shinohara et al., 1992; Adzuma et al., 1984; Emery et al., 1991; Kans and Mortimer, 1991). Little is known about the 
precise function of the products encoded by these genes and their role in DSB repair. Evidence has been presented that the RAD52 protein binds directly to the RAD51 gene product, which is homologous to the RecA protein from E. coli (Shinohara et al., 1992). This observation has been substantiated by GAL4 two-hybrid studies, which revealed a physical interaction between the C-terminal one-third of RAD52 and the RAD51 protein (Milne and Weaver, 1993). Genetic studies suggest that the RAD52 protein is not involved in the first steps of recombination. The formation of inviable spores in rad52 null mutants is not suppressed by a spo13 mutation, which eliminates the first meiotic division (Klapholz and Esposito, 1980a,b). Possible recombination intermediates have also been detected in rad52 mutant strains (Nag and Petes, 1993). Therefore, the RAD52 protein is presumably required for an intermediate or late step in recombination (Petes et al., 1991).

Homologs of RAD51, RAD52 and RAD54 have been identified in the distantly related yeast strain Schizosaccharomyces pombe (Muris et al., 1993; Ostermann et al., 1993; Muris et al., unpublished). Based on conserved amino acid domains, degenerate primers can be designed and used for the identification of mammalian homologs. In this way, RAD51 and RAD52 genes from chicken have been isolated (Bezzubova et al., 1993a,b). Recently, the mouse and human homologs of RAD51 have also been cloned (Shinohara et al., 1993; Morita et al., 1993). The structural similarity of the yeast and the mammalian homologs indicates that certain steps in the recombinational repair pathway are conserved during evolution.

Here, we report the isolation of the human and mouse RAD52 homologs. The protein sequences predicted by the two mammalian genes share extensive homology and strongly resemble the chicken and yeast homologs.

\section{Materials and methods}

\section{Gene isolation}

Two conserved stretches of six amino acids shared by the Saccharomyces cerevisiae RAD52 protein and its homolog from Schizosaccharomyces pombe, rad22, were used to design degenerate primers to clone the mouse RAD52 homolog by amplification in vitro. The sequences of the upstream and downstream oligonucleotides are 5'-GGAATTCAA(A/G)CTIGGICCIGA(A/ G)TA-3' and 5'-GGAATTCC(A/G)TAICCIAT$(\mathrm{A} / \mathrm{G}) \mathrm{TC}(\mathrm{T} / \mathrm{C}) \mathrm{TC}-\mathrm{3}^{\prime}$. I is the symbol used for inosine and alternative nucleotides are given in brackets. Restriction enzyme sites for Eco RI were included at the $5^{\prime}$ end of the primers to facilitate subcloning. Poly $\mathrm{A}^{+}$RNA from mouse testis was reverse transcribed by random priming according to the GeneAmp ${ }^{\mathrm{R}}$ RNA PCR kit (Perkin-Elmer). The reaction mixture was heated for $2 \mathrm{~min}$ at $94^{\circ} \mathrm{C}$ and used in a PCR reaction with $50 \mathrm{pmol}$ of each primer. The samples were cycled for 30 times through three temperatures: $94^{\circ} \mathrm{C}(5 \mathrm{~s})$, $42^{\circ} \mathrm{C}(15 \mathrm{~s})$ and $72^{\circ} \mathrm{C}(1 \mathrm{~min})$. Amplification products were purified on $4 \%$ Nusieve $^{\mathrm{R}}$ agarose (FMC Bioproducts) and subcloned in M13 vectors for sequence analysis.

\section{cDNA isolation and sequencing}

A 252-bp PCR-derived fragment was used to screen a mouse thymus cDNA library (kindly provided by $\mathrm{M}$. van Lohuizen) and a human testis cDNA library (Clontech). Hybridization was performed for $16 \mathrm{~h}$ at $62^{\circ} \mathrm{C}$ in $1 \mathrm{M} \mathrm{NaCl}, 1 \%$ SDS, $5 \%$ dextran sulfate, $50 \mathrm{mM}$ Tris- $\mathrm{HCl}(\mathrm{pH} 7.5), 1$ $\mathrm{mM}$ EDTA and $20 \mu \mathrm{g} / \mathrm{ml}$ salmon sperm DNA. Filters were washed to a final stringency of $1 \times$ SSC at $62^{\circ} \mathrm{C}$. After subcloning into pUC119 and pUC120 and into M13mp18 and M13mp19 vectors (Maniatis et al., 1989; Yanisch-Perron et al., 1985), the nucleotide sequence of both strands was determined using $\mathrm{T} 7$ polymerase according to the manufacturer (Pharmacia/LKB). In some cases sequencing reactions were carried out using an AutoRead sequencing kit (Pharmacia/LKB) and the products were analyzed on an ALF Automatic Sequencer (Parmacia/LKB). Deduced amino acid sequences were aligned according to the Boxshade program (Corpet, 1988).

\section{Northern analysis}

RNA was isolated from different adult mouse tissues by homogenization of frozen material in 
SCRAD 52 SPRAD 22 ChRAD 52 MmRAD 52 H S RAD 52

SCRAD 52 SPRAD 22 ChRAD 52 MmRAD 52 H S RAD 52

SCRAD 52 SPRAD 22 ChRAD 52 MmRAD 52 H S RAD 52

SCRAD 52 SPRAD 22 ChRAD 52 MmRAD 52 HSRAD 52

SCRAD 52 SPRAD 22 ChRAD 52 MmRAD 52 HSRAD 52

SCRAD 52 SPRAD2 2 ChRAD 52 MmRAD 52 HSRAD 52

SCRAD 52 SPRAD 22 ChRAD 52 MmRAD 52

H S RAD 52

SCRAD 52 SPRAD 22

ChRAD 52

MmRAD 52

H S RAD 52

SCRAD 52 SPRAD 22 ChRAD 52 MmRAD 52 HSRAD 52
1

1

1

1

1

61

36

47

47

46

119

96

105

105

104

179

156

165

165

164

239 215 219

219

218

299

271

267

270

261

356

331

310

316

306

416

385

347

352

349

476

442

399

399

400

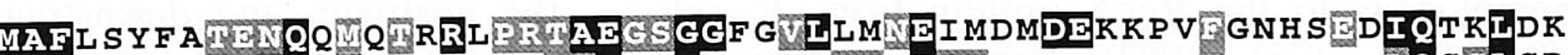

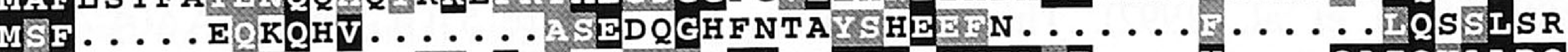

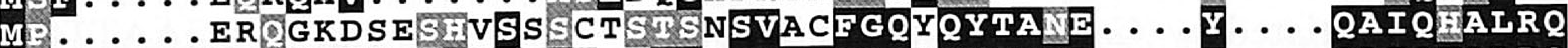

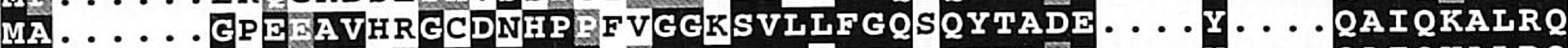
MS...... GTVIATL GRDSHPA. GGGSVICFGQCQYTAFE.... . . QAIQKALRQ

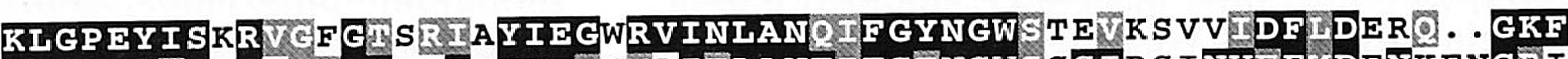

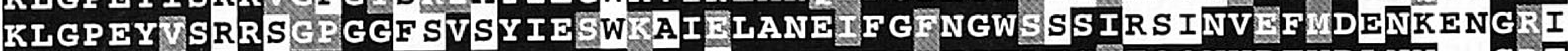
KLGP EYISSRQAGGGQKVCY IFGHIVISIANEMFG NGWAHSWTQQNVDFVDINN. . GRF RILP EY I SSRMAGGGQKVCY IEGHRV INLANEMF GYNGWAHS ITQQNVDFVDINN. . GKF L LP EY ISSRMAGGGQKVCY I EGHR V INLANEMF GYNGWAHS ITQQNVDFVDINN • GKF

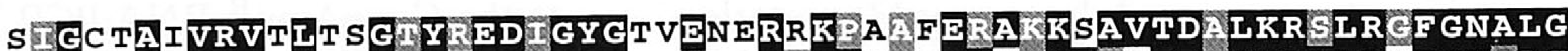

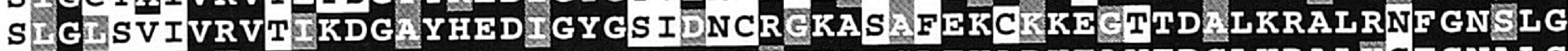
YVGVCAFVWVQIKDGS YHEDVGYGVSEGIJSKALSIEKARKEAVTDGLKRAL J̈CFGNAIG YVGVCAFV SVQIKDGSYHEDVGYGVSEGIRSKALSIEKARKEA VTDGIKRALRSFGNAIG YVGVCAFVRVQLKDGSYHEDVGYGVSEGL STALSIEKARKEAVTDGLKRALRSFGNALG

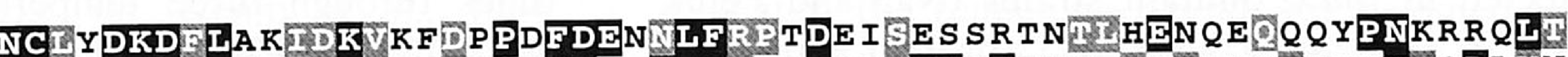
NCWYDKYYLREVGK K P TYHFDSGDLFRKTDPARRESFIKK. OKWLNSTRTVNNQPLWN

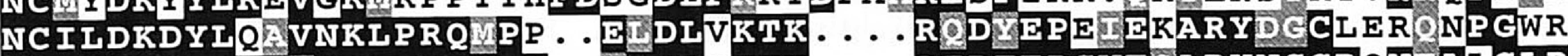
NCIIDKDYLRS NKLPRQIPI . . DVDITKTK . . . REDFEPSVEDARYNSCRQN DALIP NCIIDKDYLRS UNKLPRQLPI. . EVDITKNK . . . RODLEPSVEGARYNSCRPNMALGHP

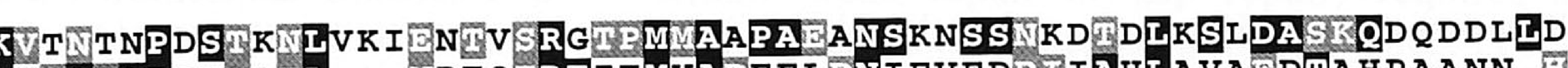

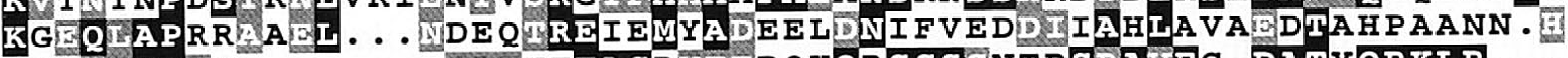

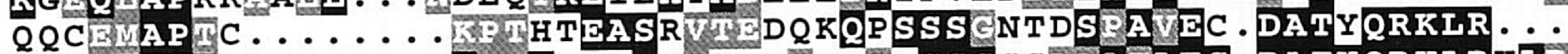

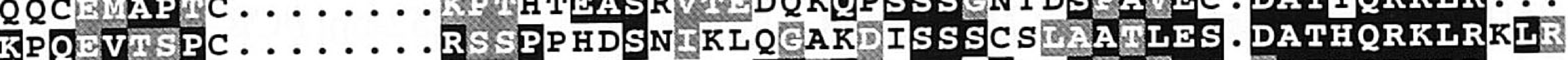

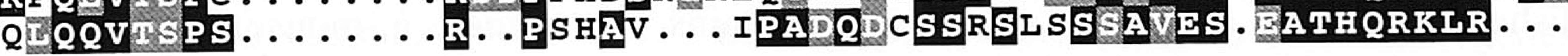

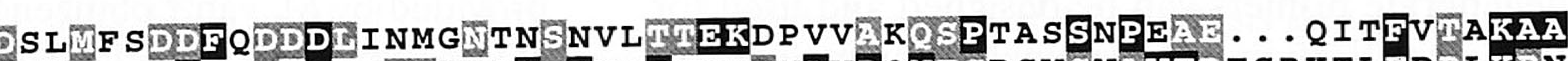

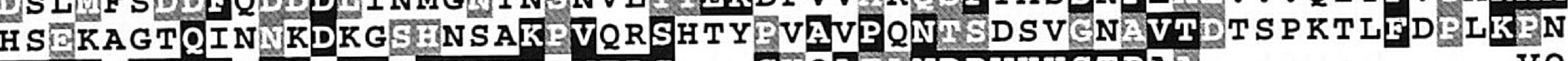
QKQI. QQQFWEQ.MFKRRQVKEVTPS...STQATHNPPVKHSTPA. ........VQ

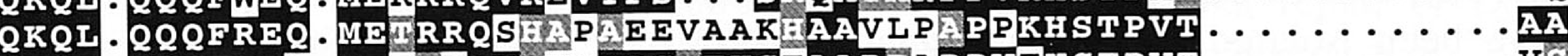

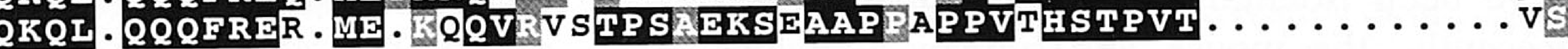

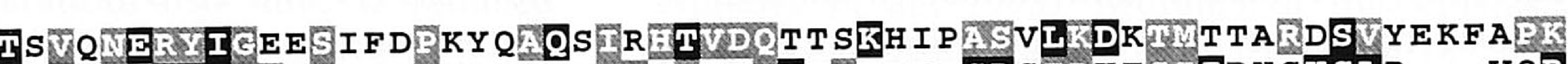

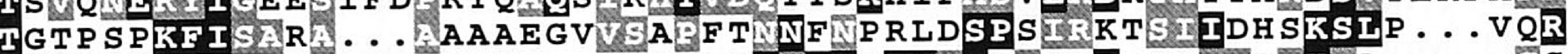

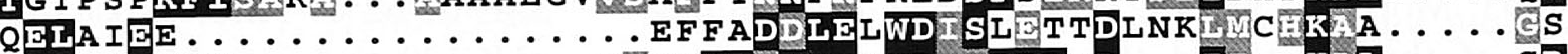

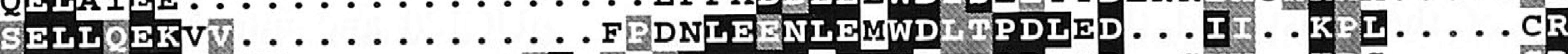

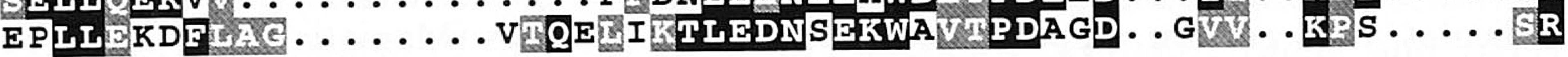

Fig. 1. Amino acid alignment of $S$. cerevisiae $(S c)$ RAD52, $S$. pombe $(S p)$ rad22, chicken $(C h)$ RAD52, mouse (Mm) RAD52 and human ( $H s$ ) RAD52 proteins. Alignments were determined using the Boxshade program (Corpet, 1988). Amino acids which are identical in at least two RAD52 homologs are highlighted in black. Highlighting in gray indicates functionally conserved amino acid residues. Conserved amino acids were taken as follows: V, I, L and M; D, E, Q and N; F, Y and W; G, S, T, P and A; K, R and H. The accession numbers of the human and mouse RAD52 nucleotide sequences are L33262 and Z32767, respectively. 
10 vol $3 \mathrm{M} \mathrm{LiCl}, 8 \mathrm{M}$ urea. After $3 \mathrm{~h}$ on ice, RNA was isolated by centrifugation and further purified by proteinase $\mathrm{K}$ treatment and phenol-chloroform-isoamyl alcohol $(25: 24: 1)$ extraction. Total RNAs (approximately $30 \mu \mathrm{g}$ ) were separated on $1 \%$ agarose, $0.6 \mathrm{M}$ formaldehyde gels, transferred to Hybond- $\mathrm{N}^{+}$(Amersham) and hybridized for $16 \mathrm{~h}$ at $42^{\circ} \mathrm{C}$ (Maniatis et al., 1989).

\section{In situ hybridization}

Mouse and human metaphase chromosomes were obtained from splenocytes and whole blood samples, respectively, as described before (Boei et al., 1994; Natarajan et al., 1991). Slides were prepared and processed for hybridization according to standard procedures (Pinkel et al., 1986). The mouse RAD52 cDNA, or a genomic RAD52 clone isolated by screening a genomic lambda library (a kind gift of G. Weeda), was used to determine the chromosomal location. To map the human RAD52 gene, the human cDNA clone was used. Specific human and mouse chromosomes were identified using a human chromosome 12 specific centromeric probe (provided by P. Devilee) and the mouse pRAF1 (Kolch et al., 1991), respectively. DNAs were labeled with a mixture of digoxigenin-11-dUTP and dTTP (1:3) in case of the centromeric specific probe and pRAF1 or with biotin-16-dUTP for the RAD52 specific probes using a nick translation kit (Promega Biotech). After labeling, the DNA was dissolved in hybridization buffer $(50 \%$ formamide, $2 \times$ SSC and $10 \%$ dextran sulfate) at a final concentration of $2.5-5 \mathrm{ng} / \mu \mathrm{l}$. To reduce background hybridization, mouse genomic probes were mixed with $5 \mu \mathrm{g}$ mouse Cot1 DNA (Gibco), denatured at $80^{\circ} \mathrm{C}$ for $10 \mathrm{~min}$, chilled on ice and incubated for $2 \mathrm{~h}$ at $37^{\circ} \mathrm{C}$ prior to use. The slides were incubated with $20 \mu \mathrm{l}$ hybridization buffer for $16 \mathrm{~h}$ in a humidified chamber at $42^{\circ} \mathrm{C}$. After hybridization, slides were washed with $50 \%$ formamide, $2 \times \mathrm{SSC}$ at $42^{\circ} \mathrm{C}$ (three times $5 \mathrm{~min}$ ) followed by three washes of $5 \mathrm{~min}$ in $0.1 \times \mathrm{SSC}$ at $60^{\circ} \mathrm{C}$. Immunological detection was carried out as described (Pinkel et al., 1988). Chromosomes were counterstained with a Vectashield antifade solution containing $1 \mu \mathrm{g} / \mathrm{ml}$ propidium iodide or
$0.15 \mu \mathrm{g} / \mathrm{ml} \mathrm{4}$,6-diamidino-2-phenylindole $\cdot 2 \mathrm{HCl}$ (DAPI).

\section{Results}

Cloning of mouse and human RAD52 homologs

The RAD52 protein from Saccharomyces cerevisiae shares two stretches of six identical amino acids at positions 61-66 and 137-142 with its counterpart from the distantly related yeast strain Schizosaccharomyces pombe, $\operatorname{rad} 22$ (see Fig. 1). These regions were used to design degenerate primers to clone part of the mouse RAD52 cDNA by amplification. Using Poly $\mathrm{A}^{+}$RNA from mouse testis as a source, a fragment of approximately 250 bp was obtained after RT-PCR. Sequence analysis revealed an open reading frame (ORF) of 252 bp with strong homology to the yeast RAD52 and $\operatorname{rad} 22$ proteins. Using the 252-bp fragment as a probe, a cDNA clone was isolated from a mouse thymus cDNA library. The same fragment was also used to isolate a human clone from a testis cDNA library. The mouse clone contains an insert of 1719 nucleotides, which is only slightly shorter than the size of the RNA species identified by Northern hybridization (see below). The first ATG at position 140 determines the start of an ORF coding for a putative polypeptide of 420 amino acids. The sequence context of the ATG codon ( $G$ CG $G$ TC AACAT$\mathrm{G} G$ ) matches perfectly to the eukaryotic consensus sequence for translation initiation (a $G$ at positions $-9,-6$ and +4 and a purine at -3 ) (Kozak, 1989). A presumed polyadenylation signal, ATTAAA, is present beginning at nucleotide 1672. The poly A tail starts at position 1692. The human cDNA clone contains an insert of 2371 bp. From position 270 to 1523 an ORF can be identified coding for a putative protein of 418 amino acid residues. In the $5^{\prime}$-untranslated region in-frame stop codons are present at positions 90 , 192, 213 and 237. The sequence context of the start codon ( $A$ GA $A$ TC $A$ AGATG $T$ ) does not match very well to the consensus sequence for start codons ( $G$ s at positions $-9,-6$ and +4 and a purine at -3 ) (Kozak, 1989). Since the homology with the mouse RAD52 protein is very 


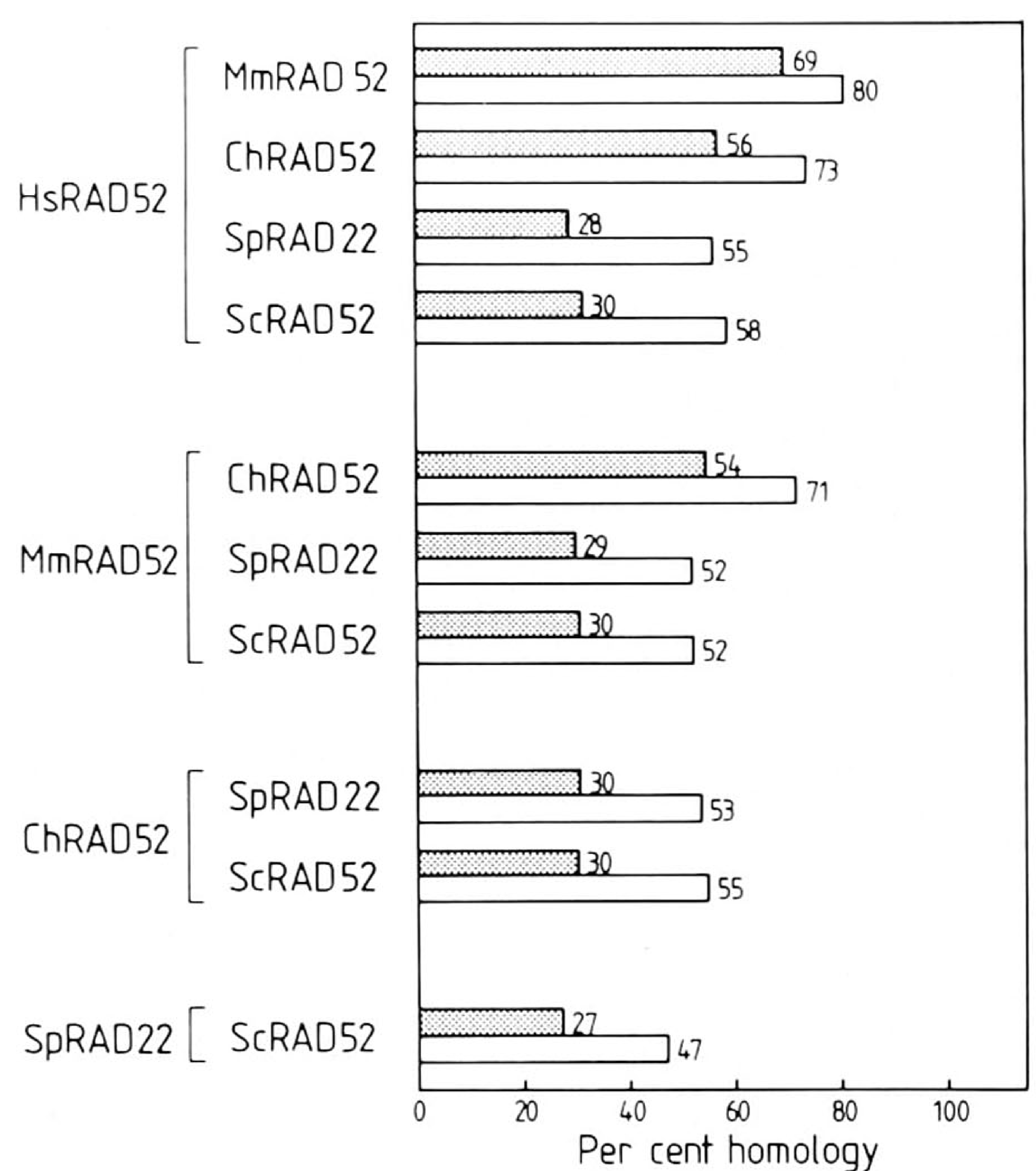

Fig. 2. Homology between pairs of RAD52 proteins. The extent of identity (dotted bars) or similarity (open bars) is given in percentages. The level of similarity includes identical and functionally conserved amino acid residues. The results are based on a pairwise comparison and may slightly deviate from the alignment of the five proteins shown in Fig. 1.

extensive in the N-terminal end (see Fig. 1), the use of a downstream ATG as a start codon is very unlikely. A potential polyadenylation signal could not be recognized and a poly A tail is not present at the end of the insert.

\section{Sequence comparison}

The alignment of amino acid sequences of $S$. cerevisiae RAD52 (Adzuma et al., 1984), S. pombe rad22 (Ostermann et al., 1993), chicken RAD52 (Bezzubova et al., 1993b), mouse RAD52 and human RAD52 proteins is shown in Fig. 1. The results of pairwise comparison of the various proteins are summarized in Fig. 2. The human RAD52 protein strongly resembles its counterparts from mouse and chicken. The identity with the mouse homolog is $69 \%$ and the overall similarity is $80 \%$. With the chicken RAD52 protein the human protein displays $56 \%$ amino acid sequence identity and $73 \%$ similarity. The homology between $S$. cerevisiae RAD52 and $S$. pombe $\operatorname{rad} 22$ is primarily concentrated in the $\mathrm{N}$-terminal region of both proteins (Ostermann et al., 1993). The region of homology between the yeast proteins and their counterparts from higher eukaryotes is also concentrated in the $\mathrm{N}$-terminal part (see Fig. 1). The stretches of conserved amino acid residues within the $\mathrm{N}$-terminal part of RAD52 proteins suggest functional importance of this region.

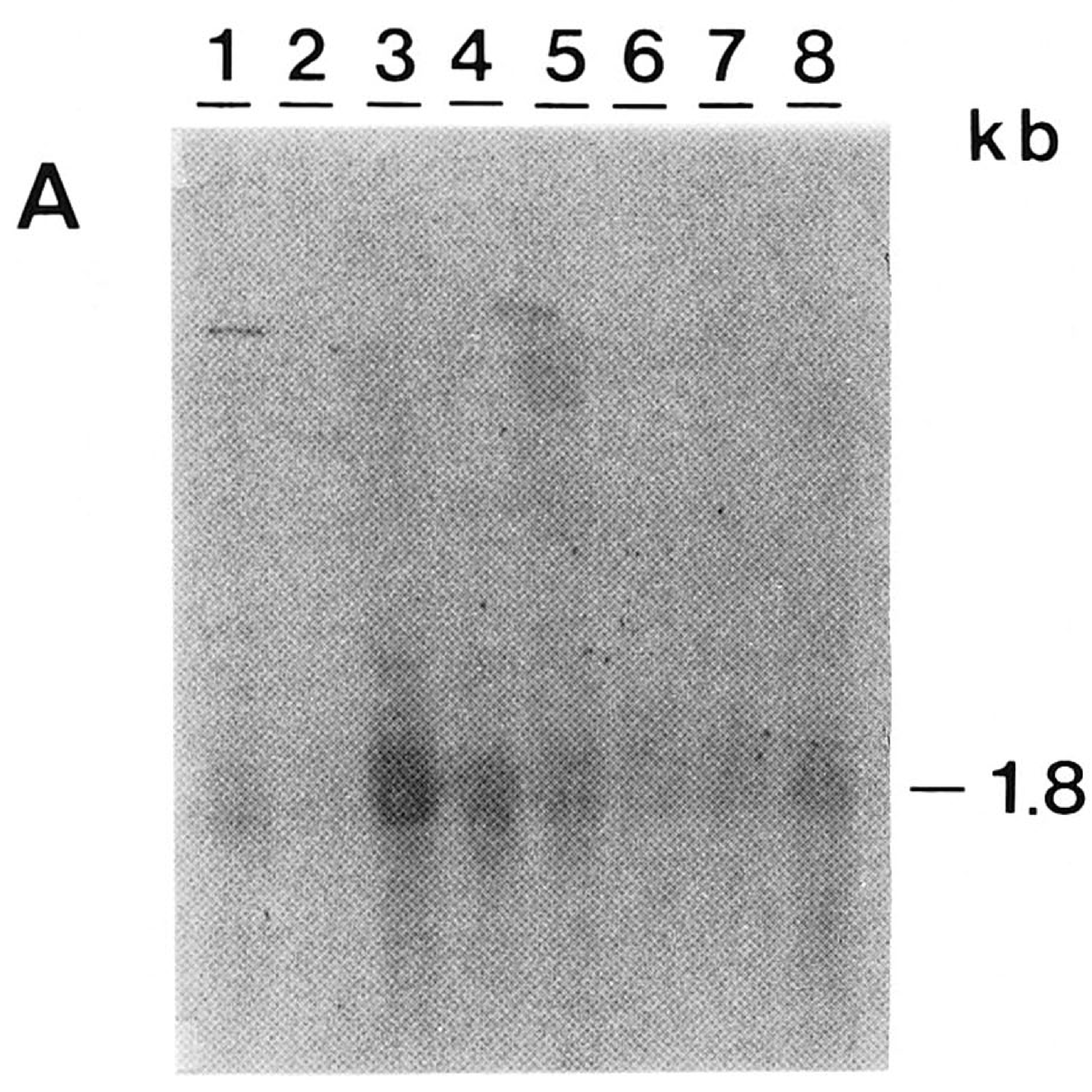

B

Fig. 3. Northern blot analysis of RAD52 expression in different adult tissues of the mouse. Lane 1: lung; lane 2: brain; lane 3: thymus; lane 4: testis; lane 5: kidney; lane 6: heart; lane 7: liver; lane 8: spleen. (A) The filter was hybridized with the insert of the mouse RAD52 cDNA clone. (B) As a control for the amount of RNA loaded, the filter was rehybridized with a HEF1 cDNA probe, encoding the human elongation factor 1 (Brands et al., 1986). 


\section{Expression of RAD52 in mouse tissues}

The expression of the mouse RAD52 gene in different tissues from adult mice was studied by Northern blot hybridization (Fig. 3). The cDNA insert hybridizes to a RNA species of about 1.8 $\mathrm{kb}$, which is in agreement with the size of the cDNA insert. The amount of RNA loaded in each lane $(30 \mu \mathrm{g})$ and the exposure time ( 2 weeks) indicate that the RAD52 gene is expressed at a very low level. The relatively highest expression levels were observed in thymus and testis.

\section{In situ hybridization}

To determine the chromosomal location of the human and mouse RAD52 genes, in situ hybridization was carried out using biotinylated probes. In case of the human gene a distinctive hybridization signal was observed on the telomeric end of the short arm of chromosome 12, as detected by the morphology of the chromosome. To confirm the identity of this chromosome a specific centromeric probe was used (Fig. 4). Based on the known banding pattern of chromo-

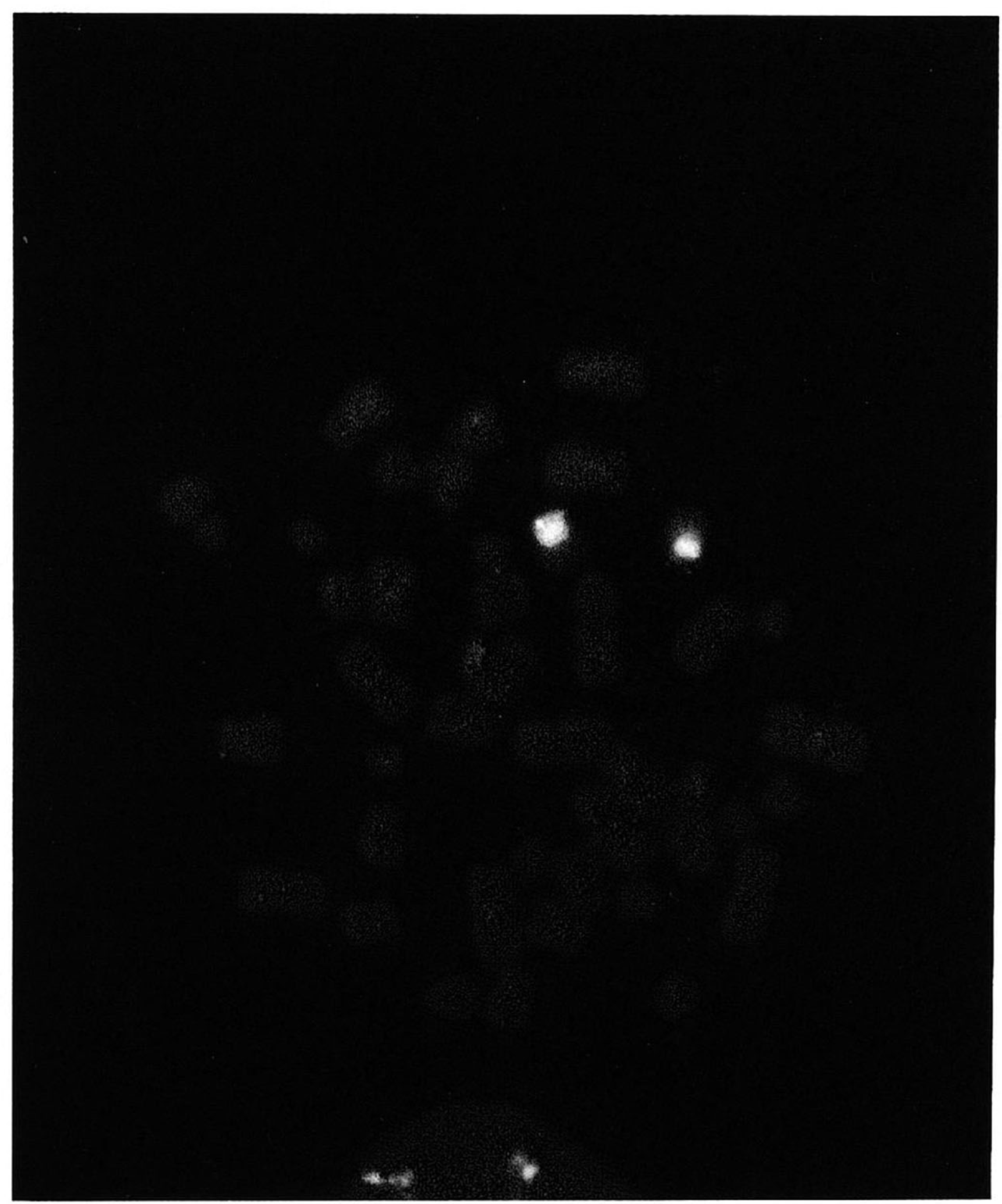

Fig. 4. Localization of the human RAD52 gene by in situ hybridization. Metaphase spreads of human chromosomes were hybridized with a biotinylated RAD52 cDNA and a digoxigenin labeled chromosome 12 specific centromeric probe. Chromosome spreads were counterstained with DAPI. The biotinylated probe gives rise to a green signal and the digoxigenin labeled probe to a red signal. 
some 12 , the $R A D 52$ gene is localized to band p13.3. The mouse RAD52 gene is located on the tip of chromosome 6 , region G3. The identity of this chromosome was confirmed by hybridization with pRAF1 (Kolch et al., 1991), a chromosome 6 specific probe (results not shown).

\section{Discussion}

The isolation of human and mouse RAD52 cDNA clones using degenerate primers based on conserved amino acid sequences of $S$. cerevisiae RAD52 and $S$. pombe rad22 is presented here. The human and mouse clones specify highly homologous proteins $(69 \%$ identity and $80 \%$ similarity). The mammalian proteins also strongly resemble the chicken RAD52 protein. The homology of the mammalian RAD52 proteins with their counterparts from $S$. cerevisiae and $S$. pombe is somewhat less. The human protein displays $58 \%$ similarity (30\% identity) with the S. cerevisiae RAD52 protein and $55 \%$ similarity (28\% identity) with the $S$. pombe $\operatorname{rad} 22$ protein. The level of conservation with the $S$. cerevisiae and $S$. pombe proteins is about the same as that between the two yeasts ( $27 \%$ identity, $47 \%$ similarity). The homology between the S. cerevisiae RAD52 protein and its homolog from the more closely related yeast Kluyveromyces lactis is more extensive (49\% identity) (Milne and Weaver, 1993).

The conservation of RAD51 homologs in evolution is much stronger. The human and mouse RAD51 proteins are almost identical and are very similar $(83 \%)$ to their counterparts from S. cerevisiae and $S$. pombe (Shinohara et al., 1993; Morita et al., 1993). The two yeast proteins display $69 \%$ identity and $83 \%$ similarity (Muris et al., 1993). Phylogenetic studies based on 5S rRNA homologies suggest that $S$. pombe is evolutionarily as far removed from $S$. cerevisiae as from man (Huysmans et al., 1983). The conservation of RAD52 and RAD51 homologs is in agreement with this observation.

The highly conserved $\mathrm{N}$-terminal region of RAD52 proteins suggests an important role in the function of this protein. This is supported by the analysis of two known $S$. cerevisiae mutant rad52 alleles. These mutations are due to basepair changes at codons 64 and 90, respectively (Adzuma et al., 1984; Boundy-Mills and Livingston, 1993). Moreover, a rad52 allele encoding only the N-terminal $65 \%$ of the protein still retains part of its repair activities (Boundy-Mills and Livingston, 1993). The C-terminal one-third of the RAD52 protein, which is required for the physical interaction with RAD51 (Milne and Weaver, 1993), is less well conserved.

The mouse RAD52 gene is expressed in all tissues analyzed, although the level is very low (Fig. 3). The relatively highest expression was observed in thymus and testis material. These results suggest the participation of the RAD52 gene product in meiotic' recombination during germ cell development and in immunoglobulin rearrangement in lymphoid tissues. Similar observations have been made in case of the chicken RAD51 and RAD52 genes and for the mouse RAD51 gene (Bezzubova et al., 1993a,b; Shinohara et al., 1993; Morita et al., 1993). The expression pattern of these genes in higher eukaryotes is compatible with the role of the RAD52 epistasis group genes in mitotic and meiotic recombination in yeast.

The human RAD52 gene is localized on chromosome 12p13.3. The mouse counterpart was assigned to region G3 of chromosome 6, which shows homology with the short arm of human chromosome 12 (Searle et al., 1989). The chromosomal location excludes the possibility that the human RAD52 gene is identical with XRCC4, $X R C C 5$ or the scid gene, which are located on chromosomes 5, 2 and 8, respectively (Giaccia et al., 1990; Chen et al., 1992; Jeggo et al., 1992; Itoh et al., 1993; Komatsu et al., 1993; Kirchgessner et al., 1993; Kurimasa et al., 1994). Therefore, the RAD52 gene may be considered another mammalian gene possibly involved in DSB repair.

The analysis of genes involved in the nucleotide excision repair pathway has shown a strong resemblance between genes from yeast and man, suggesting a functional conservation of this mode of DNA repair (Hoeijmakers, 1993a,b). The isolation and characterization of mammalian homologs of yeast genes involved in recombina- 
tional repair indicate that this repair pathway is also functionally conserved in evolution.

\section{Acknowledgements}

This work was supported by the J.A. Cohen Institute, Interuniversity Research Institute for Radiopathology and Radiation Protection (IRS; project 4.4.12) and by the Medical Genetics Centre (project MGC2). We wish to thank C. van Sluis, A. van Gool and P. van der Spek for their assistance in the alignment of the amino acid sequences and M. Zdzienicka, R. Jessberger and $\mathrm{S}$. Takeda for critical reading of the manuscript. The Basel Institute for Immunology was founded and is supported by F. Hoffmann-LaRoche \& Co. Ltd. The mouse RAD52 gene has also been isolated recently by $\mathrm{C}$. Bendixen and R. Rothstein. We would like to thank them for sharing unpublished data with us.

\section{References}

Aboussekhra, A., R. Chanet, A. Adjiri and F. Fabre (1992) Semidominant suppressors of Srs2 helicase mutations of Saccharomyces cerevisiae map in the RAD51 gene, whose sequence predicts a protein with similarities to procaryotic RecA proteins, Mol. Cell. Biol., 12, 3224-3234.

Adzuma K., T. Ogawa and H. Ogawa (1984) Primary structure of the RAD52 gene in Saccharomyces cerevisiae, Mol. Cell. Biol., 4, 2735-2744.

Ajimura, M., S-H. Leem and H. Ogawa (1993) Identification of new genes required for meiotic recombination in Saccharomyces cerevisiae, Genetics, 133, 51-66.

Alani, E., S. Subbiah and N. Kleckner (1989) The yeast $R A D 50$ gene encodes a predicted $153-\mathrm{kD}$ protein containing a purine nucleotide-binding domain and two large heptad-repeat regions, Genetics, 122, 47-57.

Basile, G., M. Aker and R.K. Mortimer (1992) Nucleotide sequence and transcriptional regulation of the yeast recombinational repair gene RAD51, Mol. Cell. Biol., 12, 3235-3246.

Bezzubova, O., A. Shinohara, R.G. Mueller, H. Ogawa and J.-M. Buerstedde (1993a) A chicken RAD51 homologue is expressed at high levels in lymphoid and reproductive organs, Nucleic Acids Res., 21, 1577-1580.

Bezzubova, O., H. Schmidt, K. Ostermann, W.-D. Heyer and J.-M. Buerstedde (1993b) Identification of chicken RAD52 homologue suggests conservation of the RAD52 recombi- nation pathway throughout the evolution of higher eukaryotes, Nucleic Acids Res., 21, 5945-5949.

Biedermann, K.A., J. Sun, A.J. Giaccia, L.M. Tosto and J.M. Brown (1991) Scid mutation in mice confers hypersensitivity to ionizing radiation and deficiency in double-strand break repair, Proc. Natl. Acad. Sci. USA, 88, 1394-1397.

Boei, J.J.W.A., A.S. Balajee, P. De Boer, W. Rens, J.A. Aten, L.H.F. Mullenders and A.T. Natarajan (1994) Construction of mouse chromosome-specific DNA libraries and their use for the detection of X-ray-induced aberrations, Int. J. Radiat. Biol., 65, 583-590.

Bosma, M.J. and A.M. Carroll (1991) The SCID mouse mutant: definition, characterization, and potential uses, Annu. Rev. Immunol., 9, 323-350.

Boundy-Mills, K.L. and D.M. Livingston (1993) A Saccharomyces cerevisiae RAD52 allele expressing a C-terminal truncation protein: Activities and intragenic complementation of missense mutations, Genetics, 133, 39-49.

Brands, J.H.G.M., J.A. Maassen, F.J. Van Hemert, R. Amons and W. Möller (1986) The primary structure of the $\alpha$ subunit of human elongation factor 1, Eur. J. Biochem., 155, 167-171.

Bryant, P.E. (1984) Enzymatic restriction of mammalian cells using PvuII and BamHI: Evidence for the double-strand break origin of chromosomal aberrations, Int. J. Radiat. Biol., 46, 57-65.

Chen, D.J., M.S. Park, E. Campbell, M. Oshimura, P. Liu, Y. Zhao, B.F. White and M.J. Siciliano (1992) Assignment of the human DNA double-strand break repair gene (XRCC5) to chromosome 2, Genomics, 13, 1088-1094.

Collins, A.R. (1993) Mutant rodent cell lines sensitive to ultraviolet light, ionizing radiation and cross-linking agents: a comprehensive survey of genetic and biochemical characteristics, Mutation Res., 293, 99-118.

Corpet, F. (1988) Multiple sequence alignment with hierarchical clustering, Nucleic Acids Res., 16, 10881-10890.

Emery, H.S., D. Schild, D.E. Kellogg and R.K. Mortimer (1991) Sequence of RAD54, a Saccharomyces cerevisiae gene involved in recombination and repair, Gene, 104, 103-106.

Fornace, A.J. and J.B. Little (1980) Normal repair of DNA single strand breaks in patients with AT, Biochim. Biophys. Acta, 607, 432-437.

Friedberg, E.C. (1988) Deoxyribonucleic acid repair in the yeast Saccharomyces cerevisiae, Microbiol. Rev., 52, 70102.

Game, J.C. (1993) DNA double-strand breaks and the RAD50-RAD57 genes in Saccharomyces, Sem. Cancer Biol., 4, 73-83.

Giaccia, A.J., R. Weinstein, J. Hu and T.D. Stamato (1985) Cell cycle-dependent repair of double-strand DNA breaks in a gamma-ray-sensitive Chinese hamster cell, Somat. Cell Mol. Genet., 11, 485-491.

Giaccia, A.J., N. Denko, R. MacLaren, D. Mirman, C. Waldren, I. Hart and T.D. Stamato (1990) Human chromosome 5 complements the DNA double-strand break-repair 
deficiency and gamma-ray sensitivity of the XR-1 hamster variant, Am. J. Hum. Genet., 47, 459-469.

Hariharan, P.V., S. Eleczko, B.P. Smith and M.C. Paterson (1981) Normal rejoining of DNA strand breaks in AT fibroblast lines after low X-ray exposure, Radiat. Res., 86, 589-597.

Hendrickson, E.A., X.Q. Qin, E.A. Bump, D.G. Schatz, M. Oettinger and D.T. Weaver (1991) A link between double-strand break-related repair and V(D)J recombination: the scid mutation, Proc. Natl. Acad. Sci. USA, 88, 4061-4065.

Hoeijmakers, J.H.J. (1993a) Nucleotide excision repair I: from E. coli to yeast, Trends Genet., 9, 173-177.

Hoeijmakers, J.H.J. (1993b) Nucleotide excision repair II: from yeast to mammals, Trends Genet., 9, 211-217.

Huysmans, E., E. Dams, A. Vandenberghe and R. De Wachter (1983) The nucleotide sequence of the 5S rRNAs of four mushrooms and their use in studying the phylogenetic position of basidiomycetes among the eukaryotes, Nucleic Acids Res., 11, 2871-2880.

Itoh, M., K. Hamatani, K. Komatsu, R. Araki, K. Takayama and M. Abe (1993) Human chromosome 8(p12-q22) complements radiosensitivity in the severe combined immune deficiency (SCID) mouse, Radiat. Res., 134, 364-368.

Ivanov, E.L., V.G. Korolev and F. Fabre (1992) XRS2, a DNA repair gene of Saccharomyces cerevisiae, is needed for meiotic recombination, Genetics, 132, 651-664.

Jaspers, N.G.J., J. de Wit, M.R. Regulski and D. Bootsma (1982) Abnormal regulation of DNA replication and increased lethality in AT cells exposed to carcinogenic agents, Cancer Res., 42, 335-341.

, Jeggo, P.A., M. Hafezparast, A.F. Thompson, B.C. Broughton, G.P. Kaur, M.Z. Zdzienicka and R.S. Athwal (1992) Localization of a DNA repair gene (XRCC5) involved in double-strand-break rejoining to human chromosome 2, Proc. Natl. Acad. Sci. USA, 89, 6423-6427.

Kans, J.A. and R.K. Mortimer (1991) Nucleotide sequence of the RAD57 gene of Saccharomyces cerevisiae, Gene, 105, 139-140.

Kemp, L.M., S.G. Sedgwick and P.A. Jeggo (1984) X-ray sensitive mutants of Chinese hamster ovary cells defective in double-strand break rejoining, Mutation Res., 132, 189196.

Kirchgessner, C.U., L.M. Tosto, K.A. Biedermann, M. Kovacs, D. Araujo, E.J. Stanbridge and J.M. Brown (1993) Complementation of the radiosensitive phenotype in severe combined immunodeficient mice by human chromosome 8, Cancer Res., 53, 6011-6016.

Klapholz, S. and R.E. Esposito (1980a) Isolation of SPO12-1 and SPO13-1 from a natural variant of yeast that undergoes a single meiotic division, Genetics, 96, 567-588.

Klapholz, S. and R.E. Esposito (1980b) Recombination and chromosome segregation during the single division meiosis in SPO12-1 and SPO13-1 diploids, Genetics, 96, 589-611.

Kolch, W., G. Heidecker, P. Lloyd and U.R. Rapp (1991) Raf-1 protein kinase is required for growth of induced NIH/3T3 cells, Nature, 349, 426-428.
Komatsu, K., T. Ohta, Y. Jinno, N. Niikawa and Y. Okumura (1993) Functional complementation in mouse-human radiation hybrids assigns the putative murine scid gene to the pericentric region of human chromosome 8, Hum. Mol. Genet., 2, 1031-1034.

Kozak, M. (1989) The scanning model for translation: An update, J. Cell Biol., 108, 229-241.

Kurimasa, A., Y. Nagata, M. Shimizu, M. Emi, Y. Nakamura and M. Oshimura (1994) A human gene that restores the DNA-repair defect in SCID mice is located on 8p11.1q11.1, Hum. Genet., 93, 21-26.

Maniatis, T., E.F. Fritsch and J. Sambrook (1989) in: N. Ford, C. Nolan and M. Ferguson (Eds.), Molecular Cloning: A Laboratory Manual, 2nd edn., Cold Spring Harbor Laboratory Press, Cold Spring Harbor, NY.

Milne, G.T. and D.T. Weaver (1993) Dominant negative alleles of RAD52 reveal a DNA repair/recombination complex including RAD51 and RAD52, Genes Dev., 7, 17551765.

Morita, T., Y. Yoshimura, A. Yamamoto, K. Murata, M. Mori, H. Yamamoto and A. Matsushiro (1993) A mouse homolog of the Escherichia coli recA and Saccharomyces cerevisiae RAD51 genes, Proc. Natl. Acad. Sci. USA, 90, $6577-6580$.

Muris, D.F.R., K. Vreeken, A.M. Carr, B.C. Broughton, A.R. Lehman, P.H.M. Lohman and A. Pastink (1993) Cloning the RAD51 homologue of Schizosaccharomyces pombe, Nucleic Acids Res., 21, 4586-4591.

Nag, D.K. and T.D. Petes (1993) Physical detection of heteroduplexes during meiotic recombination in the yeast Saccharomyces cerevisiae, Mol. Cell. Biol., 13, 2324-2331.

Natarajan, A.T. and G. Obe (1984) Molecular mechanisms involved in the production of chromosomal aberrations. III. Restriction endonucleases, Chromosoma, 90, 120-127.

Natarajan, A.T., R.C. Vyas, J. Wiegant and M.P. Curado (1991) A cytogenetic follow-up study of the victims of a radiation accident in Goiania (Brazil), Mutation Res., 247, $103-111$.

North, P., A. Ganesh and J. Thacker (1990) The rejoining of double-strand breaks in DNA by human cell extracts, Nucleic Acids Res., 18, 6205-6210.

Ostermann, K., A. Lorentz and H. Schmidt (1993) The fission yeast rad22 gene, having a function in mating-type switching and repair of DNA damages, encodes a protein homolog to Rad52 Saccharomyces cerevisiae, Nucleic Acids Res., 21, 5940-5944.

Petes, T.D., R.E. Malone and L.S. Symington (1991) in: J. Broach, J. Pringle and E. Jones (Eds.), The Molecular and Cellular Biology of the Yeast Saccharomyces, Cold Spring Harbor Laboratory Press, Cold Spring Harbor, NY, pp. 407-521.

Pinkel, D., T. Straume and J.W. Gray (1986) Cytogenetic analysis using quantitative, high sensitivity, fluorescence hybridization, Proc. Natl. Acad. Sci. USA, 83, 2934-2938.

Pinkel, D., J. Landegent, C. Collins, J. Fuscoe, R. Segraves, J. Lucas and J.W. Gray (1988) Fluorescence in situ hybridization with human chromosome-specific libraries: De- 
tection of trisomy 21 and translocations of chromosome 4, Proc. Natl. Acad. Sci. USA, 85, 9138-9142.

Price, A. (1993) The repair of ionizing radiation-induced damage to DNA, Semin. Cancer Biol., 4, 61-71.

Searle, A.G., J. Peters, M.F. Lyon, J.G. Hall, E.P. Evans, J.H. Edwards and V.J. Buckle (1989) Chromosome maps of man and mouse. IV, Ann. Hum. Genet., 53, 89-140.

Shinohara, A., H. Ogawa and T. Ogawa (1992) RAD51 protein involved in repair and recombination in $S$. cerevisiae is a RecA-like protein, Cell, 69, 457-470.

Shinohara, A., H. Ogawa, Y. Matsuda, N. Ushio, K. Ikeo and T. Ogawa (1993) Cloning of human, mouse and fission yeast recombination genes homologues to RAD51 and $\operatorname{rec} A$, Nature Genet., 4, 239-243.

Taccioli, G.E., H.-L. Cheng, A.J. Varghese, G. Whitmore and F.W. Alt (1994) A DNA repair defect in Chinese hamster ovary cells affects $\mathrm{V}(\mathrm{D}) \mathrm{J}$ recombination similarly to the murine scid mutation, J. Biol. Chem., 269, 7439-7442.

Van der Schans, G.P., H.B. Centen and P.H.M. Lohman (1980) Studies on the repair defect(s) of ataxia telangiectasia fibroblasts, Radiat. Environ. Biophys., 17, 351.
Weibezahn, K.F., H. Lohrer and P. Herrlich (1985) Doublestrand break repair and $G_{2}$ block in Chinese hamster ovary cells and their radiosensitive mutants, Mutation Res., 145, 177-183.

Whitmore, G.F., A.J. Varghese and S. Gulyas (1989) Cell cycle responses of two $\mathrm{X}$-ray sensitive mutants defective in DNA repair, Int. J. Radiat. Biol., 56, 657-665.

Winegar, R.A., J.W. Phillips, J.K. Youngblom and W.F. Morgan (1989) Cell electroporation is a highly efficient method for introducing restriction endonucleases into cells, Mutation Res., 225, 49-53.

Winegar, R.A., L.H. Lutze, J.T. Rufer and W.F. Morgan (1992) Spectrum of mutations produced by specific types of restriction enzyme-induced double-strand breaks, Mutagenesis, 7, 439-445.

Yanisch-Perron, C., J. Vieira and J. Messing (1985) Improved M13 phage cloning vectors and host strains: nucleotide sequences of the M13mp18 and pUC19 vectors, Gene, 33, $103-119$. 